\title{
CARBON FOOTPRINT ANALYSIS OF CONSTRUCTION ACTIVITIES IN SRI LANKA: AN INPUT-OUTPUT TABLE
}

\author{
GUNATHILAKE. S ${ }^{1}$, RAMACHANDRA. T² \& MADUSHIKA. U. G. D ${ }^{3}$ \\ 1,2,3 Department of Building Economics, University of Moratuwa, Sri Lanka \\ ${ }^{1}$ samgunathilake82@gmail.com, ${ }^{2}$ thanujar@uom.lk, ${ }^{3}$ dilakshimadushika96@gmail.com
}

\begin{abstract}
The construction industry is one of the major contributors that emits carbon into the environment. When considering the carbon emission in the local context, even though there are Input-Output Tables (IOTs) that applies to all types of industries in Sri Lanka, there seems to be limited focuses on IOTs specifically relating to the construction activities which is vital for the need due to its outstanding contribution to the carbon footprint of Sri Lanka. Hence, this study aims to calculate the carbon footprint construction activities in Sri Lanka using IOT with a bottom-up approach. The required data were extracted from published documents of Survey of Construction Industry by Census and Statistics, and The Inventory of Carbon and Energy (ICE) database of UK. Carbon footprint of construction activities were calculated using IOT with a bottom-up approach. The analysis revealed that the road and railway sector have the highest contribution of $48 \%$ to the monetary value of the construction industry meanwhile it accounts for $44 \%$ of the highest carbon emission to the atmosphere in the year 2020. Subsequently, activities related to non-residential residential, and utilities contribute to $20 \%, 15 \%$, and $12 \%$ of total carbon emission respectively. In terms of construction materials, cement-based activities (59\%) were the highest contributor while rubble and metal-based (23\%), and iron and steel-based activities (17\%) were next level contributors to the carbon emission due to construction. The analysis concluded that the as the initiatives, public sector projects including road and railway sector and utilities should integrate more sustainable construction practices as they are responsible for more than $50 \%$ of carbon emission.
\end{abstract}

Keywords: Carbon emission, Carbon footprint, Construction activities, Input-output table, Sri Lanka.

\section{Introduction}

Urbanization and climate change have become the topics of current interest where both influence land use with the complicated relationship between each other (Shafique et al., 2018; Chu et al., 2017). Furthermore, Barido and Marshell (2014) stated urbanization as an increasingly important determinant of greenhouse gas (GHG) emission. Subsequently, various developments are resulting in high emissions of carbon, especially in the construction industry. According to Huang et al, (2017), the construction sector consumes $40 \%$ of the raw materials and contributes to $40-50 \%$ of the greenhouse gas emissions. Even though greenhouse gas (GHG) emissions mainly consist of several gases namely Carbon Dioxide (CO2), Methane (CH4), Nitrous Oxide (N2O), Hydro Fluoro Carbon and Per Fluoro Carbons (HFCs, PFCs) as well as Sulphur Hexafluoride (SF6) emissions, the mass of each gas emitted is commonly represented in a CO2 equivalent to define total impact to a single figure (Dayarathne and Gunawardane, 2014; Goodier, 2010). Hence, it is a necessary response to reduce the carbon emission of buildings as it was identified as one of the main culprits for high carbon emission and significant attention has been paid to life cycle carbon assessments in order to reduce carbon emission which becomes one of the major challenges (Nawarathna et al., 2017). Therefore, Goodier (2010) has stated that the carbon footprint is a measure of total $\mathrm{CO}_{2}$ and other GHG emissions over the life span of a product, person, organization, or city, caused either directly or indirectly.

Carbon footprint refers to the direct and indirect carbon emissions required to satisfy a given consumption, which is measured in tonnes of $\mathrm{CO}_{2}$ equivalents, using a 100-year horizon (Fuglestvedt et al., 
2003). Various methodological frameworks have been used to measure carbon footprint. Life cycle assessment (LCA) is one such framework, which evaluates the carbon emission from production, use, and disposal of a product, activity, or set of products and set of products or activities (Finkbeiner, 2009). In general, carbon footprint analysis methods can be divided into two main types as the process analysis (PA)based LCA method, and the input-output table (IOT) based input-output analysis (IOA) method. In addition, there is a Hybrid method, which is a combination of the two approaches: bottom-up and top-down (Wiedmann and Minx, 2008).

With the rapid development of economy, the construction industry occupies a high proportion in the global economy. The development of the construction industry also brought us the destruction of nature, air pollution and other serious environmental problems (Huang et al., 2010). Similarly, according to the Department of Census and Statistics Sri Lanka (2015), the construction industry is the one of largest industry in Sri Lanka where more than 50\% the raw material use in the country.

Further, construction industry contributes to a high portion of $\mathrm{CO}_{2}$ emission to the atmosphere, hence, carbon emission analysis is vital for the construction industry. However, at present, it seems to be limited country-specific research and related data inventories on carbon emissions in Sri Lankan construction activities. Identifying the effects of construction activities on the carbon footprint would enable practitioners to establish effective policies to mitigate carbon emission with the use of alternative methods to the construction activities which are detrimental to the environment. Hence, this study aims to assess the carbon emission of construction activities by carbon footprint analysis through IOT method which is timely and highly relevant to the current requirements of the country.

\section{Literature Review}

The construction industry is one of the largest consumers of resources and raw materials, hence significantly influences the natural environment (Dimoudi and Tompa, 2008). According to Arena and de Rosa (2003), the construction industry consumed $40 \%$ of the stone, sand, and gravel, $25 \%$ of the timber, and $16 \%$ of the water in the world annually. Furthermore, the life cycle of buildings which includes construction, operation, and demolition consumes nearly $50 \%$ of the total energy demand and contributes to $50 \%$ of the CO2 emissions (Dimoudi and Tompa, 2008). In Australia, $44 \%$ of the 14 million tonnages of waste that have been collected and put into landfills each year is due to the construction/demolition industry (Songer and Molenaar, 1996). The construction industry in developing regions consumes approximately $62-86 \%$ of domestic productions of non-metallic minerals, such as cement, clay, glass, and lime, etc. (Chan and Chan, 2004).

Even though many studies have focused on energy use and GHG emissions in the life cycle of buildings, the specific focus to construction activities seemed to have received less attention. The previous studies have covered the energy usage or GHG emissions or $\mathrm{CO}_{2}$ emission in the manufacture of building materials, energy consumption of construction equipment, transportation for building materials, and disposal of construction waste (Borjesson and Gustavsson, 2000; Seo and Hwang, 2001; Guggemos and Horvath, 2005; Norman et al., 2006; Gerilla et al., 2007; Dimoudi and Tompa, 2008; Upton et al., 2008).

Klufallah et al. (2014) quantified the carbon footprint by considering the Twenty (20) units of corner double-story houses and twenty-six (26) units of intermediate environment-friendly double-story houses in Malaysia. Results of the study revealed that steel shows the highest amount of $\mathrm{CO}_{2}$ equivalent and concrete accounts for the second large carbon emission contributor among the selected major materials. Furthermore, Victoria et al. (2015) investigated the elemental contribution of carbon emission and revealed that most of the structural activities contribute over $80 \%$ to the total carbon emission of the building. Further, the above study identifies those structural activities; cement-based activities, sand-based activities, rubble and metal-based activities, bricks-based activities, timber-based activities, and the steel and iron-based activities as the most commonly used activities in the superstructure and the substructure of the building.

Carbon footprint is known to be a measure of total greenhouse gases directly or indirectly emitted due to activity over the life span of a product, person, organization, city, or even a country (Goodier, 2010). Further, Goodier (2010) stated that the carbon footprint is either included all greenhouse gases and expressed in tonnes of $\mathrm{CO}_{2}$ equivalent or included $\mathrm{CO}_{2}$ only and expressed in tonnes of $\mathrm{CO}_{2}$. At present-day, the calculation of carbon footprint is approached in two different directions. one is the bottom-up approach which is based on Process Analysis (PA) whereas the other is the top-down approach and is based on Environmental Input-Output (EIO) analysis (Wiedmann and Minx, 2008). Under the process-based 
method, all the materials and energy used in the whole process are identified and emissions will be measured whereas the economic input-output analysis considers all the direct and indirect impacts involved in the supply chain (Yan et al., 2010). The hybrid method combines both the methods; processbased method and economic input-output analysis method (Lin et al., 2013).

Although input-output analysis has benefits like low time, cost and manpower consumption, easy data collection, and perfect system boundary, it leads to a risk of final results due to the assumptions made under the model (Hong et al., 2015; Lin et al., 2013). Further, Lin et al. (2013) explained that the processbased method has a direct chance of assessing the macro level for particular stages of the process, where the input-output analysis has no such advantage. Additionally, the hybrid method may comprise of doublecounting disadvantage due to the combination of two methods and it requires severe data and time for continuation (Hong et al., 2015).

\section{Research Methodology}

In this study, a carbon footprint analysis was done through IOT method. The primary data collection was carried out by referring to documents such as the Survey of Construction Industry report 2014/2015 published by the Department of Census and Statistics Sri Lanka and ICE database published by University of Bath, UK.

The data published in the report of Census and Statistics was used as the basis to identify the main material-based activities in the construction industry. Further, since the latest version of the Census and Statistics Survey of Construction Industry report is for 2014/2015, respective values for material-based activities for the year 2020 were derived using those values.

The study used the IOT with a bottom-up approach to calculating the carbon footprint in main material-based activities in the construction industry which are identified through the Census and Statistics Survey of Construction Industry report 2014/2015. Prior to performing the carbon footprint calculations, five (5) unstructured interviews were carried out among industry professionals and academics who are very familiar with the subject matter and possess expert knowledge regarding carbon footprint calculations. Those unstructured interviews revealed that the carbon emission factors of the Index of Carbon and Energy (ICE, UK) are suitable to use in the carbon footprint calculation of the Sri Lankan construction industry due to the lack of emission factors specific to Sri Lanka and the production process of materials in the UK production industry being much more similar to the construction industry of Sri Lanka.

The carbon footprint calculations were done in accordance with the five steps shown below.

\section{Step 1:}

The monetary values of the construction work done were converted into physical values using the prices from price indices of the considered time, published by the CIDA.

$$
\text { Physical Quantity Value }=\sum_{k=0}^{n} M / P
$$

Where the " $\mathrm{M}$ " is the monetary value of the construction output or value of work done relating to the material-based activity of the considered organization and the " $\mathrm{p}$ " indicates the consumer price of the related material-based construction activity of the study.

\section{Step 2:}

The physical values of the construction work done were converted to the amount of carbon emission of the above construction activities by using the conversion factors from carbon footprint conversion factors for the company reporting index in the considered time from the government of the UK.

$$
\text { Amount of carbon emission }=(\text { Physical quantity value }) \times(\text { carbon conversion factor })
$$

Step 3:

Then the calculated figure of the carbon emissions was converted into the carbon footprint values by using the footprint factor.

$$
\text { Carbon footprint }=(\text { Amount of carbon emission }) \times \text { (Carbon footprint factor })
$$


Step 4:

The fourth step was the construction of an IOT for the calculated carbon footprint of construction activities in the Sri Lankan construction industry. The table consists of a matrix structure indicating the inter-sector industries and the material-based construction activities in Sri Lanka. However, the inter-sector industries include different sub-sectors, which are commercial, residential, roads and civil engineering, etc.

Step 5:

The above calculated IOT data were used to develop the ratios of carbon emission with regards to the relevant type of constructions in the Sri Lankan construction industry. The ratios were calculated by dividing the physical values of the carbon emission in specific sectors in 2014/15 from the total work done in each specific sector in monetary values.

$$
\text { Carbon Emission Ratio on the specific type of construction (R)= C / M }
$$

Where the " $R$ " is the carbon emission ratio on the specific type of construction, where the " $C$ " is the amount of carbon emission relating to the specific type of construction and " $\mathrm{M}$ " is the monetary value relating to the specific type of construction in the above inter-sector IOT of Sri Lanka.

The scope of this study is limited to the major material-based activities; cement-based, sandbased, rubble and metal-based, brick-based, timber-based, and iron and steel-based used in the construction industry due to the limited country specified data.

\section{Data analysis and findings}

This section presents the carbon emission from main material-based activities in the construction industry respective to different sectors (Residential buildings, non - residential buildings, roads and railways, utility projects, other civil engineering projects, electrical, plumbing and other construction activities, building completion, and finishing, and other constructions) according to the International Standards of Industrial Classifications (ISIC) Rev. 4.

As discussed in the five steps (under Research Methodology) of carbon footprint calculation based on the IOT, initially it was identified the monetary value of main material-based activities through the basis of Census and Statistics Survey of Construction Industry report 2014/2015 for the year 2020 and shown in Table 1.

\begin{tabular}{|c|c|c|c|c|c|c|c|c|c|c|c|c|c|c|c|c|}
\hline 冚 & 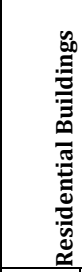 & & 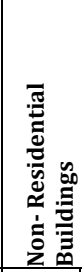 & & 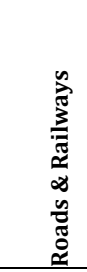 & & 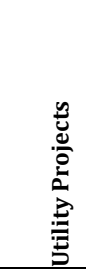 & & 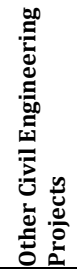 & & 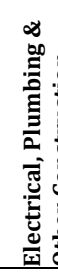 & 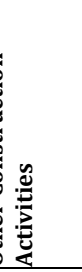 & 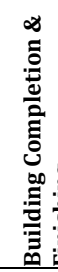 & & 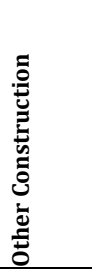 & \\
\hline $\begin{array}{l}\text { Cement } \\
\text { based }\end{array}$ & 7,980 & $19 \%$ & 9,555 & $23 \%$ & 13,953 & $33 \%$ & 5,688 & $14 \%$ & 2,912 & $7 \%$ & 109 & $0.2 \%$ & 44 & $0.1 \%$ & 1,452 & $3 \%$ \\
\hline \begin{tabular}{|l} 
Sand \\
based
\end{tabular} & 4,444 & $25 \%$ & 4,703 & $27 \%$ & 6,124 & $35 \%$ & 947 & $5 \%$ & 475 & $3 \%$ & 56 & $0.3 \%$ & 12 & $0.07 \%$ & 827 & $5 \%$ \\
\hline \begin{tabular}{|l|} 
Rubble \& \\
Metal \\
based \\
\end{tabular} & 3,744 & $5 \%$ & 9,260 & $13 \%$ & 53,005 & $72 \%$ & 5,102 & $7 \%$ & 1,167 & $2 \%$ & 33 & $0.04 \%$ & 6 & $0.01 \%$ & 1,381 & $2 \%$ \\
\hline \begin{tabular}{|l|} 
Bricks \\
based \\
\end{tabular} & 3,391 & $45 \%$ & 3,423 & $46 \%$ & 331 & $4 \%$ & 261 & $3 \%$ & 27 & $0.4 \%$ & 30 & $0.4 \%$ & 10 & $0.1 \%$ & 40 & $1 \%$ \\
\hline \begin{tabular}{|l|}
$\begin{array}{l}\text { Timber } \\
\text { based }\end{array}$ \\
\end{tabular} & 2,383 & $32 \%$ & 3,140 & $42 \%$ & 575 & $8 \%$ & 986 & $13 \%$ & 136 & $2 \%$ & 10 & $0.1 \%$ & 51 & $1 \%$ & 193 & $3 \%$ \\
\hline $\begin{array}{l}\text { Iron \& } \\
\text { Steel } \\
\text { based } \\
\end{array}$ & 6,687 & $16 \%$ & 7,459 & $17 \%$ & 18,262 & $43 \%$ & 6,253 & $15 \%$ & 1,061 & $2 \%$ & 54 & $0.1 \%$ & 418 & $1 \%$ & 2,705 & $6 \%$ \\
\hline Total & 28,628 & $15 \%$ & 37,541 & $20 \%$ & 92,250 & $48 \%$ & 19,236 & $10 \%$ & 5,779 & $3 \%$ & 293 & $0.1 \%$ & 541 & $0.2 \%$ & 6,598 & $3 \%$ \\
\hline
\end{tabular}

Table 1: Total cost (LKR) of material-based activities (2020) Rs. million

As shown in Table 1, the road and railway sectors have the highest contribution of 48\% (Rs. 92,250 $\mathrm{Mn}$ ) to the monetary value of the construction industry. Subsequent contributors to the monetary value of the construction industry are residential buildings (20\%), nonresidential buildings (15\%), and utility projects (10\%). In contrast, other civil engineering projects (3\%), other construction (3\%), building Completion and finishing (0.2\%), and electrical, plumbing, and other construction activities $(0.1 \%)$ have 
the least contribution to the monetary value of construction industry. Further different construction sectors account for the different portions in major material-based activities. Brick-based activities have the highest contribution of $46 \%$ and $45 \%$ to the non-residential and residential buildings, respectively. Rubble and metal-based activities (72\%) account for the highest contribution on road and railway projects while iron and steel-based activities (43\%) show the second-highest contribution.

Subsequently, the physical quantity of the material-based activities in kg for each construction sector was derived by using the average current market prices as shown in Table 2.

\begin{tabular}{|c|c|c|c|c|c|c|c|c|c|}
\hline 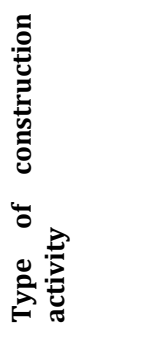 & 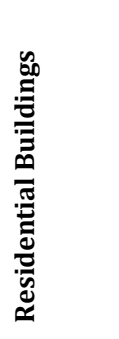 & 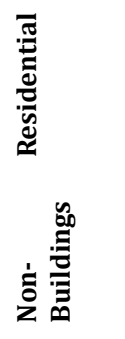 & 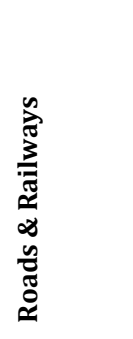 & 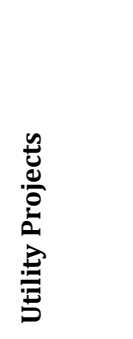 & 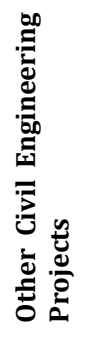 & 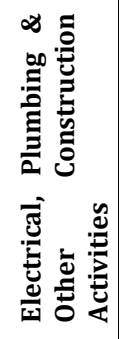 & 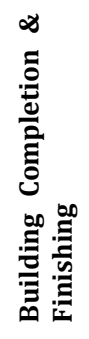 & 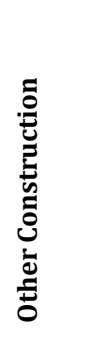 & 葆 \\
\hline $\begin{array}{l}\text { Cement } \\
\text { (kg) }\end{array}$ & 407.15 & 487.50 & 711.91 & 290.19 & 148.58 & 5.57 & 2.26 & 74.10 & $2,127.27$ \\
\hline Sand(kg) & 360.54 & 381.55 & 496.83 & 76.80 & 38.53 & 4.51 & 0.98 & 67.11 & $1,426.86$ \\
\hline $\begin{array}{l}\text { Rubble \& } \\
\text { Metal(kg) }\end{array}$ & 631.20 & $1,561.25$ & $8,936.53$ & 860.12 & 196.79 & 5.56 & 0.93 & 232.80 & $12,425.17$ \\
\hline Bricks(kg) & 0.54 & 0.55 & 0.05 & 0.04 & 0.00 & 0.00 & 0.00 & 0.01 & 1.20 \\
\hline Timber(kg) & 11.25 & 14.82 & 2.71 & 4.66 & 0.64 & 0.05 & 0.24 & 0.91 & 35.28 \\
\hline $\begin{array}{l}\text { Iron \& } \\
\text { Steel(kg) }\end{array}$ & 43.70 & 48.75 & 119.36 & 40.87 & 6.93 & 0.36 & 2.74 & 17.68 & 280.38 \\
\hline Total & $1,454.39$ & $2,494.43$ & $10,267.38$ & $1,272.67$ & 391.48 & 16.06 & 7.15 & 392.61 & $16,296.17$ \\
\hline
\end{tabular}

Table 2: Physical quantity (Kg) of total output on material based activities (million)

According to Table 2, the quantity requirement of rubble and metal is comparatively higher than the other main materials. Subsequent contributors to the quantity required for each construction sector are cement, sand, and iron, and steel. Timber and bricks have the least contribution to the quantity requirement.

As the next step of the carbon emission calculations, the physical quantity of the work done was multiplied by the carbon footprint emission factor of those materials derived from the ICE data base, UK. Table 3 represents the emission factors are calculated using the Carbon Trust, UK.

\begin{tabular}{|l|c|}
\hline Material (1Kg) & CO2 emission in Kg \\
\hline Cement & 0.830 \\
\hline Sand & 0.005 \\
\hline Rubble \& Metal & 0.056 \\
\hline Bricks & 0.620 \\
\hline Timber & 0.420 \\
\hline Iron \& Steel & 1.770 \\
\hline
\end{tabular}

Table 3: Carbon emission factors Source: (ICE database, 2019)

As per Table 3, from the above-selected materials, it was revealed that iron and steel is the largest contributor to carbon emission by their weight. The second-largest contributor is cement, and others are respectively as bricks, rubble and metal, timber, and sand.

Finally, carbon emission on the construction industry's inter-sector IOT was developed based on Equation 3 as shown in Table 4. 


\begin{tabular}{|c|c|c|c|c|c|c|c|c|c|c|}
\hline & \multicolumn{10}{|c|}{ OUTPUT (CO2 Emission in Kg) (million) } \\
\hline \multirow[t]{8}{*}{$\begin{array}{l}\mathbf{I} \\
\mathbf{N} \\
\mathbf{P} \\
\mathbf{U} \\
\mathbf{T}\end{array}$} & 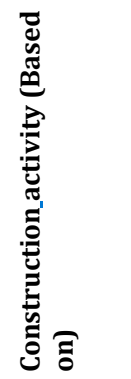 & 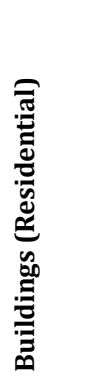 & 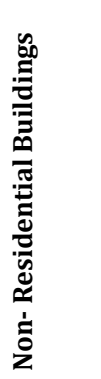 & 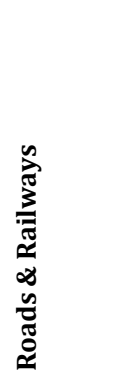 & 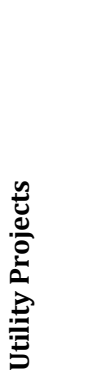 & 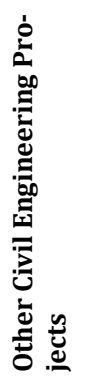 & 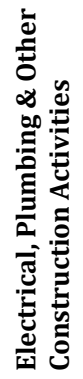 & 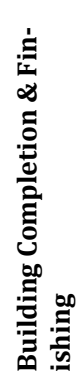 & 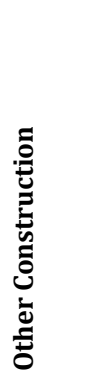 & 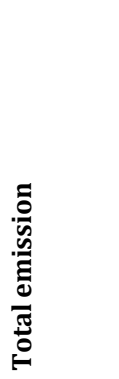 \\
\hline & Cement & 337.94 & 404.63 & 590.88 & 240.85 & 123.32 & 4.62 & 1.88 & 61.51 & $1,765.63$ \\
\hline & Sand & 1.80 & 1.91 & 2.48 & 0.38 & 0.19 & 0.02 & 0.005 & 0.34 & 7.13 \\
\hline & $\begin{array}{l}\text { Rubble \& } \\
\text { Metal }\end{array}$ & 35.35 & 87.43 & 500.45 & 48.17 & 11.02 & 0.31 & 0.05 & 13.04 & 695.81 \\
\hline & Bricks & 0.34 & 0.34 & 0.03 & 0.03 & 0.003 & 0.003 & 0.001 & 0.004 & 0.75 \\
\hline & Timber & 4.72 & 6.23 & 1.14 & 1.96 & 0.27 & 0.02 & 0.10 & 0.38 & 14.82 \\
\hline & $\begin{array}{l}\text { Iron \& } \\
\text { Steel }\end{array}$ & 77.35 & 86.29 & 211.26 & 72.34 & 12.27 & 0.63 & 4.84 & 31.29 & 496.28 \\
\hline & $\begin{array}{l}\text { Total } \\
\text { Emission }\end{array}$ & 457.50 & 586.83 & $1,306.25$ & 363.72 & 147.08 & 5.61 & 6.88 & 106.56 & $2,980.42$ \\
\hline
\end{tabular}

Table 4: Carbon emission on construction industry's inter-sector input-output table

The inter-sector IOT (Table 4) depicted that the roads and railways sector is the highest carbon emission sector in the year 2020. The roads and railways sector has emitted over 1 billion $\mathrm{kg}(44 \%)$ of carbon to the environment in the 2020 financial year. Subsequent contributors to the carbon emission in different construction sectors are non-residential (20\%), residential (15\%), utility projects (12\%), other civil engineering projects (5\%), and other construction activities (4\%), respectively. Building completion and finishing $(0.23 \%)$ and electrical, plumbing, and other construction activities $(0.19 \%)$ show the least contribution to the carbon emission. Table 4 further elaborated that the cement-based activities are the highest contributor to the total carbon emission in the 2020 financial year when compared with the other material-based activities identified in the study. Cement-based activities emitted more than 1.5 billion kilograms (59\%) of carbon to the environment in the 2020 financial year according to the inter-sector IOT. Subsequent contributors to the carbon emission in different material-based activities are rubble and metalbased activities (23\%), and iron and steel-based activities (17\%), respectively. Timber-based activities (1\%), sand-based activities (0.24\%), and brick-based activities $(0.03 \%)$ show the least contribution to the carbon emission.

According to the calculation of inter-sector, IOT (Table 4), carbon emission ratios of different types of construction sectors can be illustrated in Table 5. Carbon emission ratios were derived using Equation 4. These factors provide the carbon emission in kg per LKR for the cost that was spent for each type of construction such as residential, commercial, roads \& railways, etc.

\begin{tabular}{|l|l|}
\hline Type of construction activity & CO2 Emission Kg per LKR 1.0 \\
\hline Other Civil Engineering Projects & 0.025 \\
\hline Utility Projects & 0.019 \\
\hline Electrical, Plumbing \& Other Construction Activities & 0.019 \\
\hline
\end{tabular}




\begin{tabular}{|l|l|}
\hline Residential Buildings & 0.016 \\
\hline Non- Residential Buildings & 0.016 \\
\hline Other Construction & 0.016 \\
\hline Roads \& Railways & 0.014 \\
\hline Building Completion \& Finishing & 0.013 \\
\hline Total Construction emission & $\mathbf{0 . 0 1 6}$ \\
\hline
\end{tabular}

Table 5: Carbon emission ratios on different types of constructions

As per Table 5, it is clear that the other civil engineering projects $(0.025)$ construction category emit more carbon per LKR. The second highest carbon emission ratio of $0.019 \mathrm{CO} / \mathrm{kg} / \mathrm{LKR}$ is utility projects and the electrical, plumbing, and other construction activities. Residential, non-residential, and other construction categories account for the same carbon emission ratio of $0.016 \mathrm{CO} 2 \mathrm{~kg} / \mathrm{LKR}$. The lowest one is building completion and finishing projects and it is $0.013 \mathrm{CO} 2 \mathrm{~kg} / \mathrm{LKR}$. However, this finding is completely contrary to the findings of the inter-sector IOT, as it demonstrated road and railway construction projects as the highest quantity requirement and the carbon emission contributor in the construction industry, carbon emission ratio is limited to $0.014 \mathrm{CO} 2 \mathrm{~kg} / \mathrm{LKR}$.

\section{Conclusions}

The analysis revealed that the road and railway sector have the highest contribution of $48 \%$ (Rs. 92,250 $\mathrm{Mn})$ to the monetary value of the construction industry. As per the calculated inter-sector IOT, the highest carbon emission contributing activities in the year 2020 were cement-based activities which emit more than 1.5 billion kilograms of carbon to the environment. When it comes to the type of construction, roads and railways sector constructions have released more CO2 to the environment in the year 2020 with emitting 1.3 billion $\mathrm{kg}$ of carbon to the environment. In terms of the project cost and the carbon emission relating to the type of construction, the highest carbon emission contributor was reportedly other civil engineering works $(0.019 \mathrm{CO} 2 \mathrm{~kg} / \mathrm{LKR})$. The outcome of this study supports identifying the most effective material-based construction activities and construction sector in the Sri Lankan construction industry to promote low carbon-emitting constructions. The main limitation in conducting this study was the unavailability of country-specified data inventories regarding carbon emission in the construction industry. The development of country-specifics carbon emission data inventories is necessary for ensuring the reliability and accuracy of carbon emission studies in the construction sector.

\section{References}

Barido, D., \& Marshall, D. J. 2014. Relationship Between Urbanization and $\mathrm{CO}_{2}$ Emissions Depends on Income Level and Policy. Environmental Science \& Technology.

Borjesson, P., \& Gustavsson, L. 2000. Greenhouse Gas Balances in Building Construction: Wood Versus Concrete from Life Cycle and Forest Land-Use Perspectives. Energy Policy, 28(9), 575-588.

Chan, A. P. C., \& Chan, A. P. L. 2004. Key Performance Indicators for Measuring Construction Success. Benchmarking: An International Journal, 11(2), 203-221.

Chu, A., Lin, Y. C., \& Chiueh, P. T. 2017. Incorporating the Effect of Urbanization in Measuring Climate Adaptive Capacity. Land Use Policy, 68, 28-38.

Dayarathne, S. P., \& Gunawardane, K. D. 2014. Carbon Footprint Reduction: A Critical Study of Rubber Production in Small and Medium Scale Enterprises in Sri Lanka. Journal of Cleaner Production.

Department of Census and Statics. 2015. Survey of Construction - Final Report 2015.

Dimoudi, A., \& Tompa, C. 2008. Energy and Environmental Indicators Related to The Construction of Office Buildings. Resources, Conservation and Recycling, 53(1-2), 86-95.

Finkbeiner, M. 2009. Carbon Footprinting Opportunities and Threats. The International Journal of Life Cycle Assessment, 14(2), 91-94.

Fuglestvedt, J. S., Berntsen, T. K., Godal, O., Sausen, S., \& Skodvin, T. 2003. Metrics of Climate Change: Assessing Radiative Forcing and Emission Indicies. Climatic Changes 58, 267-331.

Gerilla, G. P., Teknomo, K., \& Hokao, K. 2007. An Environmental Assessment of Wood and Steel-Reinforced Concrete Housing Construction. Building and Environment, 42(7), 2778-2784.

Goodier, C. (2010). Carbon footprint. In N. Cohen, \& P. Robbins (Eds.), Green Cities: An A-to-Z Guide (pp. 49-53). London: 
SAGE Publication.

Guggemos, A. A., \& Horvath, A. 2005. Decision Support Tool for Environmental Analysis of Commercial Building Structures. In Construction Research Congress, 183, p. 19.

Gunathilaka, L. D. Z. F., \& Gunawardana, D. K. 2015. Carbon Footprint Calculation from Cradle to Grave: A Case Study of Rubber Manufacturing Process in Sri Lanka. International Journal of Business and Social Science, 6(10), 82-94.

Hong, J., Shen, G., Feng, Y., Lau, W., \& Mao, C. 2015. Greenhouse Gas Emissions During the Construction Phase of A Building: A Case Study In China. Journal of Cleaner Production, 103, 249-259.

Huang, B., Lei, J., Ren, F., Chen, Y., Zhao, Q., Li, S., \& Lin, Y. (2021). Contribution and obstacle analysis of applying BIM in promoting green buildings. Journal of Cleaner Production, 278. doi:10.1016/j.jclepro.2020.123946

Huang, W., Li, F., Cui, S., Huang, L., \& Lin, J. 2017. Carbon Footprint and Carbon Emission Reduction of Urban. Procedia Engineering, 198, pp. 1007-1017.

ICE Data Base. (2019). The Inventory of Carbon and Energy Data Base. UK: University of Bath. Retrieved from https://circularecology.com/embodied-carbon-footprint-database.html

Klufallah, M. M. a., Nuruddin, M. F., Khamidi, M. F., \& Jamaludin, N. 2014. Assessment of Carbon Emission Reduction for Buildings Projects in Malaysia-A Comparative Analysis. E3S Web of Conferences, 3(1016), 1-8.

Lin, J., Liu, Y., Meng, F., Cui, F., \& Xu, L. 2013. Using Hybrid Method to Evaluate Carbon Footprint of Xiamen City, China. Energy Policy, 58, 220-227.

Nawarathna, R., Fernando, N., \& Perera, S. 2017. Estimating Whole Life Cycle Carbon Emissions of Buildings: A Literature Review. What's New and What's Next in the Built Environment Sustainability Agenda? Colombo

Norman, J., MacLean, H., \& Kennedy, C. 2006. Comparing High and Low Residential Density: Life-Cycle Analysis of Energy Use and Greenhouse Gas Emissions. Journal of Urban Planning Development, 132(1), 10-21.

Seo, S., \& Hwang, Y. 2001. Estimation of $\mathrm{CO}_{2}$ Emissions in Life Cycle of Residential Buildings. Journal of Construction Engineering and Management, 127(5), 414-418.

Shafique, M., Kim, R., \& Rafiqe, M. 2018. Green Roof Benefits, Opportunities, And Challenges - A Review. Renewable and Sustainable Energy Reviews, 90, 757-773.

Songer, A. D., \& Molenaar, K. R. 1996. Selecting Design-Build: Public and Private Sector Owner Attitudes. Journal of Management in Engineering, 12(6), 47-53.

Upton, B., Miner, R., Spinney, M., \& Heath, L. S. 2008. The Greenhouse Gas and Energy Impacts of Using Wood Instead of Alternatives in Residential Construction in The United States. Biomass and Bioenergy, 32(1), 1-10.

Vitoria, M.F., Perera, S., Davis, A. and Fernando, N. 2017. Carbon and Cost Critical Elements: A Comparative Analysis of Two Office Buildings. Built environment project and asset management, 7(5), pages 460-470.

Wiedmann, T., \& Minx, J. 2008. A Definition Of “Carbon Footprint” - Chapter 1. In Ecological Economics Research Trends, pp. 1-11. 